\title{
ANALISA KEBUTUHAN AIR DALAM KECAMATAN BANDA BARO KABUPATEN ACEH UTARA
}

\author{
Susilah \\ Dosen Jurusan Teknik Sipil, Universitas Malikussaleh \\ email:zulfhazli.abdullah@gmail.com
}

\begin{abstract}
Abstrak
Kecamatan Banda Baro merupakan pemekaran dari Nisam yang mempunyai luas $42,35 \mathrm{~km}^{2}$ atau $4.235 \mathrm{Ha}$ dengan jumlah penduduk 7.377 jiwa. Dari luas daerah tersebut areal lahan persawahan yaitu $1.093 \mathrm{Ha}$ dan lahan campuran 3.142 Ha. Dengan bertambahnya jumlah penduduk dapat diprediksikan untuk 5 tahun yang akan datang yaitu sebesar 8.553 jiwa, maka kebutuhan airnya juga bertambah yaitu sebanyak $0,0091 \mathrm{~m}^{3} /$ det. Sedangkan untuk 10 tahun yang akan datang jumlah penduduknya sebesar 9.724 jiwa dan jumlah kebutuhan airnya sebesar $0,0103 \mathrm{~m}^{3} /$ det. Untuk 25 tahun yang akan datang jumlah penduduknya adalah sebesar 14.291,41 jiwa dengan jumlah kebutuhan air sebanyak $0,0151 \mathrm{~m}^{3} /$ det dan untuk 50 tahun yang akan datang, maka jumlah penduduknya semakin meningkat pesat yaitu sebesar 27.149,329 jiwa dan kebutuhan airnya juga semakin banyak yaitu 0,0287 $\mathrm{m}^{3} /$ det. Demikian juga kebutuhan air untuk peternakan unuk tahun 2012 yaitu sebesar $0,0041 \mathrm{~m}^{3} /$ det, dapat diprediksikan untuk 5 tahun yang akan datang yaitu sebesar $0,0060 \mathrm{~m}^{3} / \mathrm{det}$, untuk 10 tahun yang akan datang yaitu sebesar $0,0089 \mathrm{~m}^{3} /$ det, untuk 25 tahun yang akan datang yaitu sebesar $0,0281 \mathrm{~m}^{3} / \mathrm{det}$, untuk 50 tahun yang akan datang yaitu sebesar $0,1614 \mathrm{~m}^{3} / \mathrm{det}$. Kebutuhan air untuk pertanian/persawahan yaitu sebesar $18,987 \mathrm{~m}^{3} / \mathrm{det}$, berdasarkan data tersebut maka kebutuhan air untuk kecamatan Banda Baro dapat diakumulasikan yaitu kebutuhan air untuk tahun 2012 yaitu sebesar 19,00 $\mathrm{m}^{3} /$ det, untuk 5 tahun yang akan datang yaitu sebesar $19,00 \mathrm{~m}^{3} / \mathrm{det}$, untuk 10 tahun yang akan datang yaitu sebesar $19,01 \mathrm{~m}^{3} /$ det, untuk 25 tahun yang akan datang yaitu sebesar $19,03 \mathrm{~m}^{3} /$ det, untuk 50 tahun yang akan datang yaitu sebesar $19,18 \mathrm{~m}^{3} /$ det.
\end{abstract}

Kata Kunci: Kebutuhan air rumah tangga, Kebutuhan air peternakan, Kebutuhan air persawahan, Curah hujan efektif, Debit intake.

\section{Pendahuluan}

Kecamatan Banda Baro merupakan salah satu Kecamatan yang ada di Kabupaten Aceh Utara. Kecamatan Banda Baro merupakan hasil pemekaran dari Kecamatan Nisam yang mulai terbentuk pada tahun 2007. Kecamatan Banda Baro mempunyai luas $42,35 \mathrm{~km}^{2}$ atau sebesar $4.235 \mathrm{Ha}$ dengan jumlah penduduk 7.523 jiwa yang terdiri dari 2 Kemukiman yaitu Kemukiman Banda Baro dan Kemukiman Lhok Weng. Kecamatan Banda Baro terdiri dari 9 Desa yaitu Jamuan, Alue Keurinyai, Blang Pala, Sangkelan, Ulee Nyeue, Paya Uleue, Cot Jabet, Paya Dua dan Paya Beunyot. Dari luas daerah tersebut areal lahan persawahan yaitu $1.093 \mathrm{Ha}$ dan lahan campuran 3.142 Ha. Berdasarkan sumber penghasilan masyarakat Kecamatan Banda Baro, $90 \%$ bermata pencaharian sebagai petani baik petani sawah atau petani kebun selebihnya bermata pencaharian sebagai peternak, pegawai negeri atau honorer dan pedagang. 
Selama ini, kebutuhan terhadap air bagi masyarakat Kecamatan Banda Baro baik untuk mengairi lahan persawahan, kebutuhan air untuk peternakan dan kebutuhan air untuk rumah tangga hanya berdasarkan musim penghujan. Waduk yang dapat dimanfaatkan sebagai sarana penampungan air masih dalam proses pelaksanaan kontruksi. Berdasarkan uraian kondisi diatas, maka dibutuhkan adanya analisa untuk mengetahui kebutuhan air terhadap segala kegiatan dalam Kecamatan Banda Baro baik untuk rumah tangga, peternakan maupun pertanian. Analisa ini memuat teknik perhitungan kebutuhan air yang diperlukan dengan metode-metode yang telah biasa digunakan pada analisa-analisa serupa.

Krueng Jamuan merupakan salah satu sungai yang dapat dimanfaatkan untuk memenuhi berbagai kebutuhan akan air. Mengingat kebutuhan air yang semakin meningkat maka diperlukan analisa yang relevan terhadap kebutuhan air dalam Kecamatan Banda Baro.

Penelitian ini bertujuan untuk mengetahui besarnya kebutuhan air dalam Kecamatan Banda Baro untuk mengatasi segala kebutuhan terhadap air untuk mengairi lahan persawahan, kebutuhan air untuk peternakan dan kebutuhan air untuk rumah tangga. Penelitian ini merupakan analisa terhadap kebutuhan air yang diharapkan dapat bermanfaat bagi masyarakat dalam sektor pertanian, peternakan, dan rumah tangga.

Analisa ini memuat teknik perhitungan kebutuhan air yang dibutuhkan dengan metode-metode yang telah biasa digunakan pada analisis-analisis serupa. Langkah-langkah perhitungan yang digunakan untuk mendapatkan besarnya kebutuhan air dalam Kecamatan Banda Baro melalui data-data yang telah ada yaitu data jumlah penduduk, data jumlah hewan ternak, data curah hujan dan data luas areal persawahan, dari data tersebut dilanjutkan dengan perhitungan kebutuhan air diantaranya kebutuhan air rumah tangga, peternakan dan persawahan. Untuk kebutuhan air rumah tangga diperoleh dengan cara survey langsung kepada masyarakat Kecamatan Banda Baro, nilai yang diambil adalah nilai rata-rata, kemudian nilai tersebut dimasukkan dalam rumus kebutuhan air rumah tangga.

\section{Tinjauan Kepustakaan}

\subsection{Kebutuhan Air}

Menurut Razuardi (2005), kebutuhan air merupakan akumulasi dari kebutuhan air seperti kebutuhan air untuk rumah tangga, peternakan dan persawahan. Untuk menentukan kebutuhan air dapat digunakan persamaan sebagai berikut :

$$
Q_{K A}=Q_{R T}+Q_{T}+Q_{S}
$$

di mana:

$\mathrm{Q}_{\mathrm{KA}}=$ Kebutuhan air

$\mathrm{Q}_{\mathrm{RT}}=$ Kebutuhan air rumah tangga

$\mathrm{Q}_{\mathrm{T}} \quad=$ Kebutuhan air ternak

$\mathrm{Q}_{\mathrm{S}} \quad=$ Kebutuhan air sawah 


\subsubsection{Kebutuhan air rumah tangga}

Menurut (Razuardi, 2005), setiap tahun jumlah penduduk bertambah berdasarkan ketentuan yang dikeluarkan oleh BPS (Badan Pusat Statistik, untuk menghitung pertumbuhan penduduk dapat digunakan persamaan sebagai berikut:

$$
P_{t}=P_{o}(1+E)^{t}
$$

di mana:

$\mathrm{Pt} \quad=$ Jumlah penduduk tahun ke $\mathrm{t}$

Po = Jumlah penduduk awal

$\mathrm{E} \quad=$ Tingkat pertumbuhan penduduk

$\mathrm{T} \quad=$ Jumlah tahun

Untuk menghitung kebutuhan air rumah tangga dapat digunakan persamaan sebagai berikut:

$Q R T=$ Pt $x$ Jumlah Air untuk rumah tangga

\subsubsection{Kebutuhan air peternakan}

Untuk jumlah populasi ternak prediksi T tahun dapat digunakan rumus (2.2) dengan angka pertumbuhan ternak berdasarkan jumlah populasi setiap tahunnya dan berdasarkan jumlah di lapangan. Untuk menghitung kebutuhan air ternak dapat digunakan persamaan sebagai berikut:

$Q T=$ Pt $x$ Jumlah Air untuk hewan

\subsubsection{Kebutuhan air persawahan}

Menurut (Wiyono, 2000), kebutuhan air persawah/irigasi sebagai gambaran umum dapat diperkirakan besarnya adalah 1 liter/detik/hektar. Akan tetapi untuk perhitungan secara akurat ditentukan oleh faktor-faktor berikut ini, yaitu:

1. Kebutuhan air bersih untuk penyiapan lahan

Kebutuhan air bersih untuk penyiapan lahan umumnya menentukan kebutuhan maksimum air irigasi. Pada tanaman padi diperlukan penyiapan lahan berupa perendaman sehingga mendapatkan kelembaban yang cukup untuk ditanami (Anonim, 1986). Besarnya kebutuhan air untuk penyiapan lahan ditentukan oleh faktor-faktor berikut ini, yaitu jangka waktu untuk penyiapan lahan dan jumlah air untuk penjenuhan dan lapisan air. Pada umumnya waktu untuk penyiapan lahan berkisar antara 30 sampai dengan 45 hari. Besarnya kebutuhan air selama penyiapan lahan dapat dihitung dengan rumus yang dikembangkan oleh van de Goor dan Zijlstra (1986), dikutip dari Anonim (1986), yaitu sebagai berikut :

$$
\begin{aligned}
& I R=\frac{M \mathrm{x}^{\mathrm{k}}}{\left(\mathrm{e}^{\mathrm{k}}-1\right)} \\
& M=\mathrm{E}_{\mathrm{o}}+\mathrm{P} \\
& k=\frac{\mathrm{M} \mathrm{x} \mathrm{T}}{\mathrm{S}}
\end{aligned}
$$

di mana:

IR = kebutuhan air untuk penyiapan lahan ( $\mathrm{mm} / \mathrm{hari})$

$\mathrm{M} \quad=$ kebutuhan air untuk mengganti kehilangan air akibat evaporasi dan perkolasi di sawah yang telah dijenuhkan tanahnya ( $\mathrm{mm} / \mathrm{hari})$ 


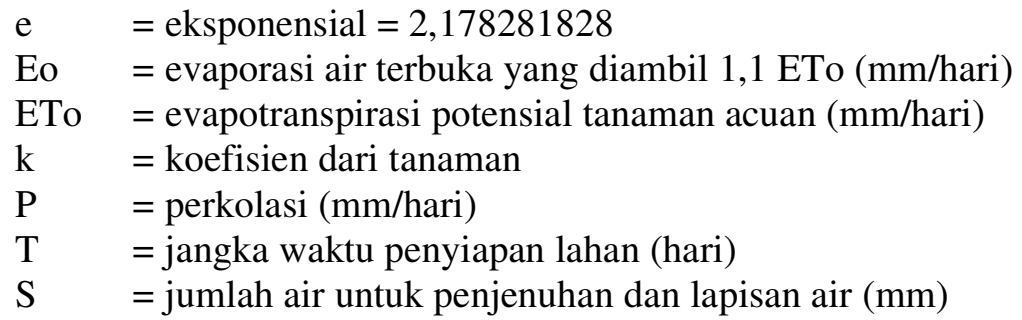

2. Kebutuhan Air Penggunaan Konsumtif Tanaman (ETc)

Kebutuhan air konsumtif dipengaruhi oleh evapotranspirasi. Evapotranspirasi adalah gabungan dari evaporasi dengan transpirasi yang terjadi secara bersamaan. Evaporasi adalah berubahnya air menjadi uap yang bergerak dari permukaan tanah atau permukaan air ke udara. Transpirasi adalah penguapan yang terjadi melalui tanaman. Besarnya kebutuhan air untuk penggunaan konsumtif tanaman dapat dihitung berdasarkan metode prakira empiris dengan menggunakan data iklim dan koefesien tanaman pada tahap pertumbuhan yaitu dengan menggunakan persamaan berikut ini:

$$
E T_{c}=\mathrm{k}_{\mathrm{c}} \times \mathrm{ET}_{\mathrm{o}}
$$

di mana:

$\mathrm{ET}_{\mathrm{c}}=$ kebutuhan air untuk penggunaan konsumtif tanaman $(\mathrm{mm} / \mathrm{hari})$

$\mathrm{k}_{\mathrm{c}} \quad=$ koefisien tanaman

ETo $=$ Evapotranspirasi

a. Koefisien tanaman

Untuk menghitung penggunaan konsumtif, besarnya evapotranspirasi dipengaruhi oleh koefisien tanaman. Pemilihan harga koefisien tanaman tergantung kepada jenis tanaman, waktu tanam, usia tanaman dan kondisi iklim (Anonim, 1986).

b. Evapotranspirasi potensial

Evapotranspirasi dihitung dengan metoda Penman Modifikasi (Sudjawardi, 1979). Metoda ini membutuhkan data yang sangat lengkap dibandingkan dengan metoda-metoda yang lain sehingga memberikan hasil yang lebih memuaskan. Persamaan Penman modifikasi dirumuskan sebagai berikut :

$$
E T_{o}=\mathrm{c} \times\left[\mathrm{W} \times \mathrm{R}_{\mathrm{n}}+(1-\mathrm{W}) \times \mathrm{f}(\mathrm{u}) \times(\mathrm{ea}-\mathrm{ed})\right]
$$

di mana:

c = faktor yang menunjukkan pengaruh perbedaan kecepatan angin pada siang dengan malam hari.

$\mathrm{W}=$ faktor pembobot.

$\mathrm{Rn} \quad=$ energi radiasi bersih yang menghasilkan evaporasi (mm/hari).

$\mathrm{f}(\mathrm{u})=$ fungsi kecepatan angin rata-rata yang diukur pada ketinggian $2 \mathrm{~m}$ dengan satuan kecepatan angin dalam (km/hari).

(ea-ed) $=$ perbedaan tekanan uap jenuh dengan tekanan uap aktual (mbar). 
3. Kebutuhan Air Untuk Perkolasi dan Rembesan

Berdasarkan Standar Perencanaan Irigasi (KP - 01, 1986), perkolasi adalah gerakan air dalam tanah dengan arah vertikal ke bawah. Menurut (Anonim, 1986), perkolasi adalah gerakan air mengalir di dalam tanah yang lajunya bergantung dengan sifat dan jenis tanah, topografi, Permukaan air tanah dan tebalnya lapisan tanah permukaan.

4. Kebutuhan Air Untuk Pergantian Lapisan Air

Pergantian lapisan air setinggi $50 \mathrm{~mm}$ dilakukan dua kali, yaitu satu bulan setelah pemindahan bibit ke petak sawah (transplantasi) dan dua bulan setelah transplantasi. Pergantian lapisan air setinggi $50 \mathrm{~mm}$ ini disimbulkan dengan WLR dan dapat diberikan :

1) Selama setengah bulan, berarti diberikan

$$
W L R=\frac{50 \mathrm{~mm}}{15 \text { hari }}=3,3 \mathrm{~mm} / \text { hari }
$$

2) Selama satu bulan, berarti diberikan

$$
W L R=\frac{50 \mathrm{~mm}}{30 \text { hari }}=1,7 \mathrm{~mm} / \text { hari }
$$

\section{Curah Hujan Efektif}

Menurut (Alfiansyah, 2004), untuk menentukan ketersediaan air berdasarkan curah hujan efektif yang ditentukan untuk setiap setengah bulanan, yaitu merupakan hujan $70 \%$ dari hujan berpeluang terpenuhi $80 \%$. Dengan kata lain, hujan ini berpeluang gagal $20 \%$. Ketersediaan air merupakan debit dari suatu sumber air yang diharapkan disadap dengan resiko kegagalan tertentu. Untuk menentukan curah hujan efektif dapat digunakan persamaan :

$$
\operatorname{Re}=0,70 x \frac{R_{80 \%}(\text { setengahbulanan })}{15} .
$$

di mana:

$$
\begin{aligned}
& \mathrm{Re} \quad=\text { hujan efektif ( } \mathrm{mm} / \text { hari) } \\
& \mathrm{R}_{80 \%} \text { (setengah bulanan) = hujan setengah bulanan berpeluang }
\end{aligned}
$$

Untuk probabilitas (peluang) terpenuhi, maka dapat dihitung dengan menggunakan persamaan :

$$
P=\frac{m}{n+1} x 100 \%
$$

di mana:

$\mathrm{P} \quad=$ probabilitas $(\%)$

$\mathrm{m} \quad=$ nomor urut data setelah diurut dari besar ke kecil

$\mathrm{n} \quad=$ jumlah tahun data

6. Kebutuhan Air di Sawah untuk Padi (NFR).

Kebutuhan air bersih di sawah (NFR) untuk padi dihitung dengan rumus :

$$
N F R=\mathrm{ET}_{\mathrm{c}}+\mathrm{WLR}+\mathrm{P}-\mathrm{Re}
$$




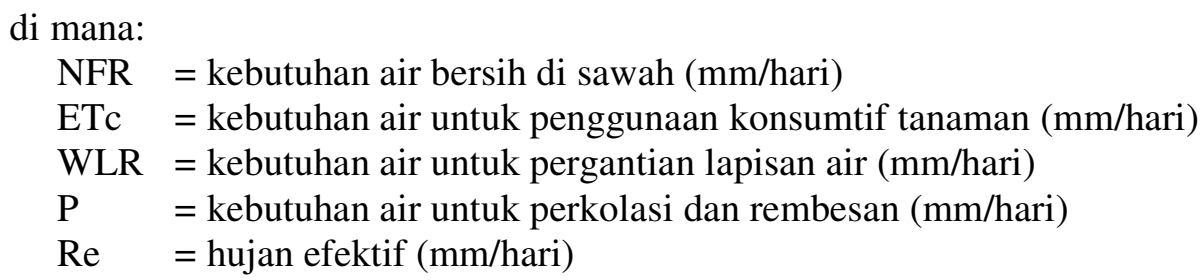

7. Kebutuhan Pengambilan untuk Padi

Kebutuhan pengambilan (DR) untuk padi adalah jumlah debit air yang dibutuhkan oleh 1 (satu) hektar sawah untuk menanam padi. Kebutuhan pengambilan ini dapat dihitung dengan menggunakan persamaan

$$
D R=\frac{\mathrm{NFR}}{\text { ef } \times 8,64}
$$

di mana:

DR = kebutuhan pengambilan $(1 /$ det $/$ ha $)$

ef = efisiensi irigasi, biasanya diambil sebesar $65 \%$

$1 / 8,64=$ angka konversi $(\mathrm{mm} /$ hari menjadi $1 /$ det $/$ ha $)$

8. Debit Intake untuk Padi

Menurut (Anonim, 1986), debit intake untuk padi adalah debit yang disadap dan kemudian dialirkan ke dalam saluran irigasi untuk memenuhi kebutuhan air irigasi saat menanam padi. Debit intake dapat dihitung dengan menggunakan persamaan berikut ini :

$$
Q=\frac{\mathrm{DR} \times \mathrm{A}}{1000}
$$

di mana:

$$
\begin{aligned}
& \mathrm{Q}=\text { debit intake }\left(\mathrm{m}^{3} / \mathrm{det}\right) \\
& \mathrm{DR}=\text { kebutuhan pengambilan }(1 / \text { det } / \mathrm{ha}) \\
& \mathrm{A}=\text { luas area irigasi (ha) } \\
& 1 / 1000=\text { angka konversi satuan liter ke } \mathrm{m}^{3}
\end{aligned}
$$

\section{Metode Penelitian}

Dalam melakukan penelitian ini digunakan metodelogi untuk pengumpulan dan pengolahan data. Setiap perencanaan atau penelitian membutuhkan berbagai data. Dalam metode pengumpulan data ini menggunakan data primer dan data sekunder. Pengumpulan data primer dilakukan dengan cara survey langsung di lapangan dan wawancara dengan masyarakat setempat. Data jumlah kebutuhan air rumah tangga dari masyarakat berdasarkan kebutuhan perhari rata-rata tiap keluarga dengan jumlah sampel $5 \%$ dari jumlah penduduk perdesa. Dengan nilai rata-rata tersebut dimasukkan dalam rumus yang ada. Pengumpulan data sekunder merupakan data yang diperoleh dengan tinjauan kepustakaan dan instansional dari instansi-instansi terkait, meliputi pengumpulan data angka dan peta. Adapun data ini diperoleh dari Instasional untuk studi ini adalah data curah hujan harian maksimum tahunan dikumpulkan dari pos hujan di sekitar lokasi analisa yang bersumber dari BMKG Stasiun Meteorologi Lhokseumawe. Data tersebut mempunyai panjang catatan mulai dari tahun 2003 s/d 2012. Data jumlah penduduk dan peta Kecamatan Banda Baro yang bersumber dari kantor Camat Banda Baro 
Untuk menghitung kebutuhan air rumah tangga berdasarkan jumlah jumlah penduduk. Setiap tahun jumlah penduduk semakin bertambah, hal ini diperlihatkan berdasarkan data yang dikeluarkan oleh BPS (Badan Pusat Statistik). Dalam menghitung pertumbuhan penduduk dapat digunakan persamaan (2.2), selanjutnya menghitung kebutuhan air rumah tangga berdasarkan jumlah rata-rata kebutuhan air yang diperoleh dari survey langsung di lapangan dikali dengan jumlah penduduk, untuk menghitung kebutuhan air untuk rumah tangga dapat digunakan persamaan (2.3). Dalam menghitung kebutuhan air untuk peternakan, maka terlebih dahulu juga harus dihitung jumlah populasi ternak dengan menggunakan persamaan (2.4). Setelah angka pertumbuhan ternak berdasarkan populasi setiap tahunnya diperoleh, maka selanjutnya dilakukan perhitungan untuk mengetahui kebutuhan air untuk peternakan dapat digunakan persamaan (2.3). Kebutuhan air untuk persawahan ditentukan oleh beberapa faktor yaitu diantaranya kebutuhan air untuk penyiapan lahan, penggunaan konsumtif tanaman, perkolasi dan rembesan, pergantian lapisan air dan curah hujan efektif. Perhitungannya dapat dilakukan dengan menggunakan persamaan (2.6) sampai dengan persamaan (2.13).

\section{$4 \quad$ Hasil dan Pembahasan}

\subsection{Analisa Kebutuhan Air}

Analisa kebutuhan air terdiri dari kebutuhan air rumah tangga, peternakan dan persawahan. Dari hasil perhitungan dapat diperlihatkan bahwa dengan bertambahnya jumlah pengguna air sungai maka kebutuhan air juga semakin meningkat.

\subsubsection{Kebutuhan air untuk rumah tangga}

Berdasarkan jumlah pertumbuhan penduduk dengan periode $\mathrm{T}$ tahun diperoleh data prediksi untuk 5 tahun yang akan datang yaitu sebesar 8.553,185 jiwa, maka kebutuhan airnya juga bertambah yaitu sebanyak 769.786,65 liter/hari atau $0,0091 \mathrm{~m}^{3} /$ det. Sedangkan untuk 10 tahun yang akan datang jumlah penduduknya sebesar $9.724,4415$ jiwa dan jumlah kebutuhan airnya sebesar $875.199,74$ liter/hari atau $0,0103 \mathrm{~m}^{3} /$ det. Sementara untuk 25 tahun yang akan datang jumlah penduduknya adalah sebesar 14.291,41 jiwa dengan jumlah kebutuhan air sebanyak 1.286.226,9 liter/hari atau $0,0151 \mathrm{~m}^{3} /$ det dan untuk 50 tahun yang akan datang, maka jumlah penduduknya semakin meningkat pesat yaitu sebesar 27.149,329 jiwa dan kebutuhan airnya juga semakin banyak yaitu 2.43.439,61 liter/hari atau $0,0287 \mathrm{~m}^{3} /$ det. Hasil perhitungan kebutuhan air untuk rumah tangga diperihatkan dalam tabel rekapitulasi kebutuhan air untuk rumah tangga dibawah ini :

Tabel 1 Rekapitulasi Kebutuhan Air Rumah Tangga

\begin{tabular}{|c|c|c|}
\hline \multirow{2}{*}{ Prediksi } & Jumlah penduduk & Kebutuhan Air \\
\hline & Jiwa & $\mathrm{m} 3 / \mathrm{det}$ \\
\hline sekarang & 7,523 & 0.0080 \\
\hline 5 tahun & 8,553 & 0.0091 \\
\hline 10 tahun & 9,724 & 0.0103 \\
\hline 25 tahun & 14,291 & 0.0151 \\
\hline 50 tahun & 27,149 & 0.0287 \\
\hline
\end{tabular}


Berdasarkan tabel tersebut, dapat ditampilkan juga dalam bentuk grafik berikut ini:

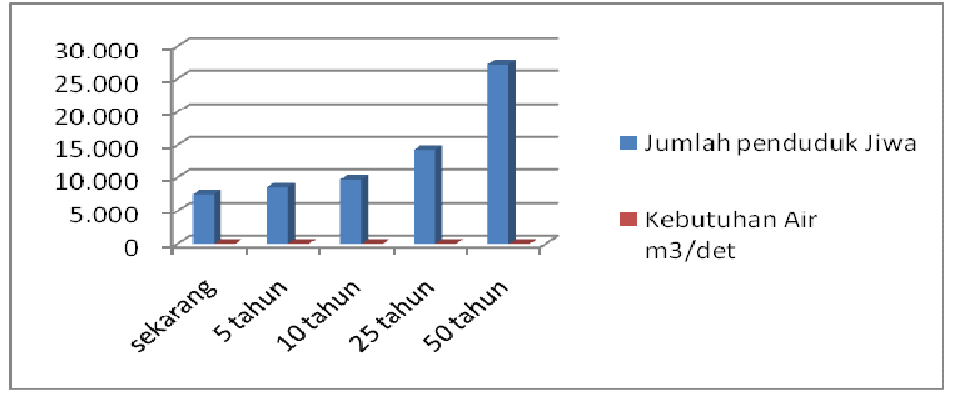

Gambar 1. Grafik Kebutuhan Air Untuk rumah Tangga

\subsubsection{Kebutuhan air untuk peternakan}

Selain untuk rumah tangga, air sungai tersebut juga digunakan untuk kebutuhan peternakan. Dimana ternak yang menggunakan air tersebut meliputi lembu, kerbau, domba, kambing, ayam dan itik. Dengan meningkatnya jumlah populasi ternak tersebut maka semakin meningkat pula nilai kebutuhan air untuk ternak-ternak. Hasil pertumbuhan populasi ternak dan nilai kebutuhan air dapat dilihat pada tabel 2 berikut ini:

Tabel 2. Rekapitulasi Kebutuhan Air untuk Ternak

\begin{tabular}{|l|c|c|c|c|c|c|c|c|}
\hline \multirow{3}{*}{ Prediksi } & \multicolumn{7}{|c|}{ Kebutuhan Air (m3/det) } & \multirow{2}{*}{$\begin{array}{c}\text { Jumlah } \\
\text { Total }\end{array}$} \\
\cline { 2 - 9 } & $\begin{array}{c}\text { Sapi / } \\
\text { Lembu }\end{array}$ & Kerbau & Kambing & Domba & $\begin{array}{c}\text { Ayam } \\
\text { Buras }\end{array}$ & $\begin{array}{c}\text { Ayam } \\
\text { Pedaging }\end{array}$ & Itik & \\
\hline Sekarang & 0.0007 & 0.00017 & 0.00047 & 0.00016 & 0.00082 & 0.00122 & 0.00056 & 0.0041 \\
\hline 5 tahun & 0.0011 & 0.00024 & 0.00068 & 0.00023 & 0.00121 & 0.00179 & 0.00082 & 0.0060 \\
\hline 10 tahun & 0.0016 & 0.00036 & 0.00101 & 0.00034 & 0.00177 & 0.00262 & 0.00120 & 0.0089 \\
\hline 25 tahun & 0.0049 & 0.00113 & 0.00319 & 0.00108 & 0.00562 & 0.00832 & 0.00380 & 0.0281 \\
\hline 50 tahun & 0.0338 & 0.00775 & 0.02186 & 0.00739 & 0.03851 & 0.02605 & 0.02605 & 0.1614 \\
\hline
\end{tabular}

Berdasarkan tabel tersebut, dapat ditampilkan juga dalam bentuk grafik seperti berikut ini :

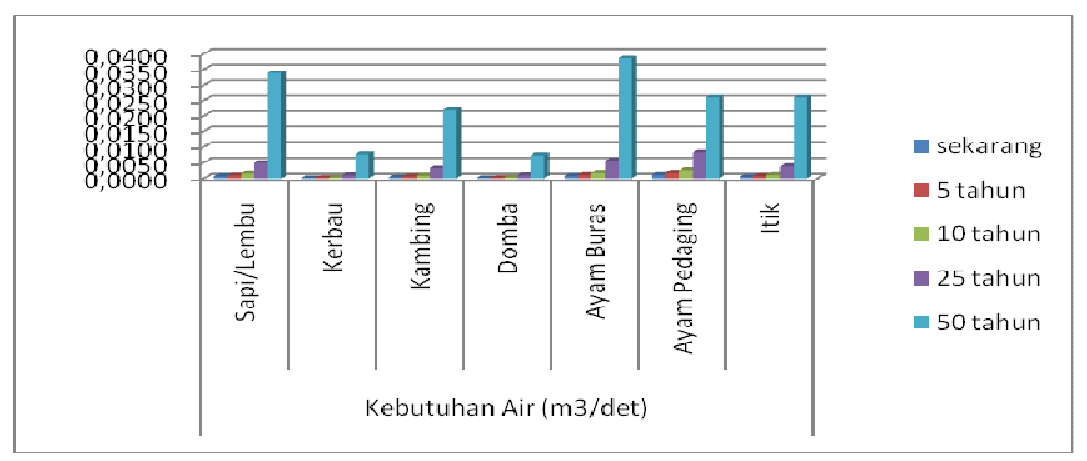

Gambar 2. Grafik Kebutuhan Air Untuk Ternak 


\subsubsection{Kebutuhan air untuk persawahan}

Kebutuhan air di sawah unuk padi sangat ditentukan oleh faktor-faktor sebagai berikut yaitu :.

a. Kebutuhan air untuk penyiapan lahan

b. Kebutuhan air untuk penggunaan konsumtif tanaman

c. Kebutuhan air untuk perkolasi dan rembesan

d. Kebutuhan Air Untuk Pergantian Lapisan Air

e. Curah Hujan Efektif

f. Kebutuhan air di sawah untuk padi

g. Kebutuhan Pengambilan untuk padi

h. Menghitung debit intake untuk padi

\subsection{Kebutuhan Air untuk Kecamatan Banda Baro}

Berdasarkan hasil perhitungan kebutuhan air rumah tangga, kebutuhan air untuk peternakan dan kebutuhan air persawahan untuk sekarang dan prediksi 5, 10, 25 dan 50 tahun yang akan datang, maka dapat direkap sebagai berikut:

Tabel 3. Rekapitulasi Kebutuhan Air untuk Kecamatan Banda Baro.

\begin{tabular}{|l|r|r|r|r|}
\hline \multirow{2}{*}{ Kondisi } & \multicolumn{4}{|c|}{ Kebutuhan Air (m3/det) } \\
\cline { 2 - 5 } & Rumah Tangga & Peternakan & Persawahan & \multicolumn{1}{c|}{ Total } \\
\hline sekarang & 0.0080 & 0.0041 & 18.987 & 19.00 \\
\hline 5 tahun & 0.0091 & 0.0060 & 18.987 & 19.00 \\
\hline 10 tahun & 0.0103 & 0.0089 & 18.987 & 19.01 \\
\hline 25 tahun & 0.0151 & 0.0281 & 18.987 & 19.03 \\
\hline 50 tahun & 0.0287 & 0.1614 & 18.987 & 19.18 \\
\hline
\end{tabular}

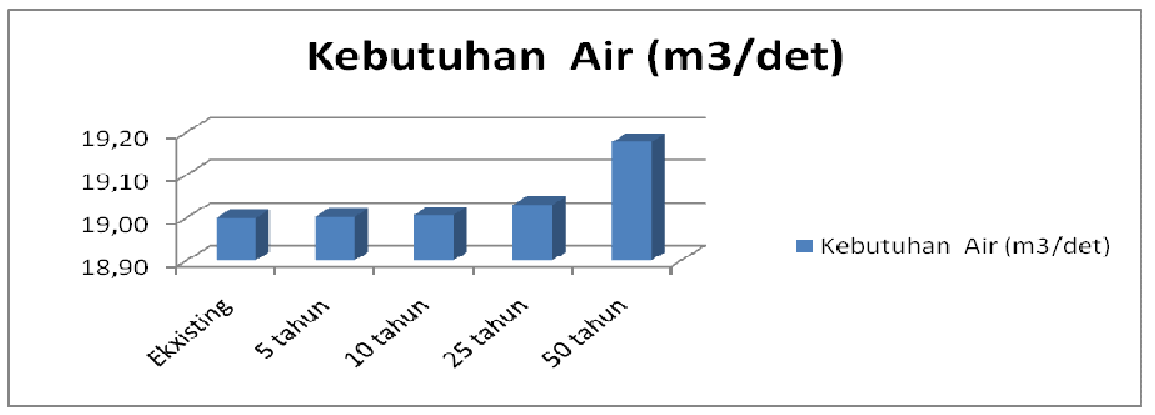

Gambar 3. Grafik Kebutuhan Air Dalam Kecamatan Banda Baro

\section{Kesimpulan dan Saran}

\subsection{Kesimpulan}

Kesimpulan-kesimpulan yng dapat diambil dari hasil analisa data dan perhitungan yang telah dilakukan yaitu sebagai berikut :

1. Pada Tahun 2012 Kecamatan Banda Baro mempunyai jumlah penduduk sebesar 7.523 jiwa. Dengan persentase pertumbuhan sebesar $2.6 \%$ dapat diprediksi banyaknya jumlah penduduk untuk 5 tahun yang akan datang yaitu 8.553 Jiwa, untuk 10 tahun yang akan datang yaitu 9.724 Jiwa, untuk 25 
tahun yang akan datang yaitu 14.291 Jiwa dan jumlah penduduk untuk 50 tahun yang akan datang yaitu 27.149 Jiwa.

2. Kebutuhan air pada saat sekarang yaitu sebesar $18,99 \mathrm{~m}^{3} / \mathrm{det}$, berdasarkan pertumbuhan penduduk dapat diprediksikan kebutuhan air untuk 5 tahun yang akan datang yaitu $19.00 \mathrm{~m}^{3} /$ det, Sedangkan untuk 10 tahun yang akan datang jumlah kebutuhan airnya sebesar $19.00 \mathrm{~m}^{3} / \mathrm{det}$, untuk 25 tahun yang akan datang jumlah kebutuhan air sebanyak $19,01 \mathrm{~m}^{3} /$ det dan untuk 50 tahun yang akan datang kebutuhan airnya juga semakin banyak yaitu $19.13 \mathrm{~m}^{3} /$ det.

\subsection{Saran}

Dari hasil penelitian hal-hal yang disarankan yaitu sesuai dengan kesimpulan yang telah diperoleh diantaranya :

1. Mengadakan pemasangan pos hujan di DAS Krueng Jamuan

2. Diperketatnya aturan tentang penebangan hutan oleh pemerintah, agar DAS dapat terjaga dengan baik dan dapat menghindari terjadinya banjir.

3. Diadakannya pemasangan jalur pipa dari PDAM untuk mendistribusikan kebutuhan air bersih dalam Kecamatan Banda Baro karena sebagian besar desa-desa dalam Kecamatan Banda Baro sangat kekurangan air bersih terutama untuk kebutuhan air rumah tangga.

4. Diharapkan kepada Pemerintah untuk segera merealisasikan pembangunan waduk Teupin Keube Krueng Jamuan, agar kebutuhan air masyarakat Kecamatan Banda terhadap persawahan dapat terpenuhi.

5. Adanya penelitian lebih lanjut tentang analisa ini agar lebih sempurna.

\section{Daftar Kepustakaan}

1. Anonim, 2010 Banda Baro Dalam Angka, BPS dan Bappeda, Aceh Utara.

2. Anonim, 1986, Pedoman Pekerjaan Ketersediaan Air, Badan Penerbit Departemen Pekerjaan Umum, Jakarta.

3. Alfiansyah. YBC, 2004, Debit Intake Irigasi, Jurusan Teknik Sipil Universitas Syiah Kuala, Banda Aceh.

4. Direktorat Jenderal Pengairan, 1997, Standar Perencanaan Irigasi (KP-01), Badan Penerbit Pekerjaan Umum, Jakarta.

5. Razuardi, Ir., MT., 2005, Pengaruh Optimasi Infiltrasi Tata Guna Lahan Di Banda Aceh Tahun 2010, Jurusan Teknik Sipil Universitas Syiah Kuala, Banda Aceh.

6. Wiyono, A., 2000, Pengembangan Sumber daya Air, Departemen Teknik Sipil - ITB, Diktat. Penerbit ITB, Bandung. 